\title{
EFFECT OF PIOGLITAZONE AND GEMFIBROZIL ADMINISTRATION ON C-REACTIVE PROTEIN LEVELS IN NON-DIABETIC HYPERLIPIDEMIC RATS Mazhar Hussain $^{\unrhd \otimes}$, Mahwash Malik', Zujaja Zaheer ${ }^{3}$,
}

ABSTRACT

OBJECTIVES: To assess and compare anti-inflammatory effect of pioglitazone and gemfibrozil by measuring C-reactive protein (CRP) levels in high fat fed non-diabetic rats.

METHODS: A comparative animal study was conducted at the Post Graduate Medical Institute, Lahore, Pakistan in which 27 adult healthy male Sprague Dawley rats were used. The rats were divided into three groups. Hyperlipidemia was induced in all three groups by giving hyperlipidemic diet containing cholesterol I.5\%, coconut oil $8.0 \%$ and sodium cholate $1.0 \%$. After four weeks, Group A (control) was given distilled water, Group B was given pioglitazone $10 \mathrm{mg} / \mathrm{kg}$ body weight and Group $C$ was given gemfibrozil $10 \mathrm{mg} / \mathrm{kg}$ body weight as single morning dose by oral route for four weeks. CRP was estimated at zero, $4^{\text {th }}$ and $8^{\text {th }}$ week.

RESULTS: There was significant increase in the level of CRP after giving high lipid diet from $($ mean $\pm S D) 2.59 \pm 0.28 \mathrm{mg} / \mathrm{L}, 2.63 \pm 0.32 \mathrm{mg} / \mathrm{L}$ and $2.67 \pm 0.23 \mathrm{mg} / \mathrm{L}$ at 0 week to $3.55 \pm 0.44 \mathrm{mg} / \mathrm{L}, 3.59 \pm 0.34 \mathrm{mg} / \mathrm{L}$ and $3.6 \pm 0.32 \mathrm{mg} / \mathrm{L}$ at $4^{\text {th }}$ week in groups $\mathrm{A}, \mathrm{B}$ and $\mathrm{C}$ respectively.

Multiple comparisons by ANOVA revealed significant difference between groups at $8^{\text {th }}$ week only. Post hoc analysis disclosed that CRP level was significantly low in pioglitazone treated group having mean $\pm S D$ of $2.93 \pm 0.33 \mathrm{mg} / \mathrm{L}$ compared to control group $4.42 \pm 0.30 \mathrm{mg} / \mathrm{L}$ and gemfibrozil group $4.28 \pm 0.39 \mathrm{mg} / \mathrm{L}$. The $\mathrm{p}$-value in each case was $<0.00 \mathrm{I}$, while difference between control and gemfibrozil was not statistically significant.

CONCLUSION: Pioglitazone is effective in reducing hyperlipidemia associated inflammation, evidenced by decreased CRP level while gemfibrozil is not effective.

KEY WORDS: Pioglitazone (MeSH); Gemfibrozil (MeSH); Hyperlipidemia $(\mathrm{MeSH})$; Anti-inflammatory $(\mathrm{MeSH})$; C-reactive protein $(\mathrm{MeSH})$.

THIS ARTICLE MAY BE CITED AS: Hussain M, Malik M, Zaheer Z, Chiragh S. Effect of pioglitazone and gemfibrozil administration on C-reactive protein levels in non-diabetic hyperlipidemic rats. Khyber Med Univ J 2018;10(3):131-4.

\section{INTRODUCTION}

nflammation plays an integral role in the pathogenesis of cardiovascular events.' One of the potential inflammatory markers is C-reactive protein (CRP), an acute phase substance that shows extent of inflammation and has proved to be an independent as well as a combined risk factor in a number of cardiovascular diseases. ${ }^{2}$ CRP induces endothelial cells to produce monocyte chemotactic
protein-I leading to expression of intercellular adhesion molecule-I and vascular adhesion molecule-I by them. Furthermore, CRP stimulates the monocyte release of pro-inflammatory cytokines that contribute the pathogenesis of the cardiovascular disease. ${ }^{3}$ Multiple clinical trials and medical investigations involve measurement of CRP in cardiac and vascular diseases. Various studies have predicted the role of serum high sensitivity C-reactive protein in determining serum
$\mathrm{I}^{凶}$ Department of Pharmacology, Sheikh Zayed Medical College/Hospital, Rahim Yar Khan, Pakistan

Email:mazharhussain214@gmail.com Contact \# : +92-321 6723330

2 Department of Pharmacology, Avicenna Medical College, Lahore, Pakistan

3 Department of Pharmacology, King Edward Medical University, Lahore, Pakistan

4 Department of Pharmacology, Postgraduate Medical Institute, Lahore, Pakistan

Date Submitted: October 26, 2017

Date Revised: September 22, 2018

Date Accepted: September 25, 2018

lipid profile fluctuations in response to dietary interventions, suggesting that these changes depend on the individual's baseline CRP levels. ${ }^{4}$ For example, men with high baseline serum CRP concentration had increased fasting cholesterol, triglycerides, low density lipoprotein cholesterol (LDL-cholesterol) level after consuming a high fat diet. Similarly, low baseline serum CRP concentration has opposite effect. ${ }^{4}$

Among the pharmaceutical interventions, statins are the best choice for cardiovascular diseases so far. Apart from their hypolipidemic action, they also exert anti-inflammatory actions ${ }^{5}$ by stimulating the expression of peroxisome proliferator-activated receptor gamma(PPAR- $-{ }^{6}{ }^{6}$ Gemfibrozil, a PPAR $\alpha$ agonist, is also used as a cholesterol lowering-agent. Since its approval by the FDA in 1982, it has been used extensively as a lipid regulating drug and is an effective treatment of hypertriglyceridemia and hypercholesterolemia. ${ }^{\text {? }}$

Pioglitazone is a member of the thiazolidinediones (TZDs) family of antidiabetic agent that stimulates the peroxisome proliferator-activated receptor-y and $\alpha$. In addition to its beneficial effects on glucose and lipid metabolism, this gene has multiple effects including anti-inflammatory properties. ${ }^{8}$ Clinical studies have shown that it is able to reduce inflammatory markers such as CRP in diabetic as well as non-diabetic patients. ${ }^{9}$ Activation of PPAR-y by pioglitazone as well as simvastatin reduce the inflammatory markers in patients of ischemic heart disease with metabolic syndrome."

We have previously shown that pioglitazone improves serum lipid profile in male Sprague Dawley hyperlipidemic 
TABLE I: EFFECT OF PIOGLITAZONE AND GEMFIBROZIL ADMINISTRATION ON C-REACTIVE PROTEIN LEVELS OF NON-DIABETIC HYPERLIPIDEMIC RATS $(n=9)$

\begin{tabular}{|c|c|c|c|c|}
\hline Weeks & Group A (Control) & Group B (Pioglitazone) & Group C (Gemfibrozil) & P value by ANOVA \\
\hline 0 & $2.59 \pm 0.28 \mathrm{mg} / \mathrm{L}$ & $2.63 \pm 0.32 \mathrm{mg} / \mathrm{L}$ & $2.67 \pm 0.23 \mathrm{mg} / \mathrm{L}$ & 0.828 \\
\hline 4 & $3.55 \pm 0.44 \mathrm{mg} / \mathrm{L}$ & $3.59 \pm 0.34 \mathrm{mg} / \mathrm{L}$ & $3.6 \pm 0.32 \mathrm{mg} / \mathrm{L}$ & $0.95 \mathrm{I}$ \\
\hline 8 & $4.42 \pm 0.30 \mathrm{mg} / \mathrm{L}$ & $2.93 \pm 0.33 \mathrm{mg} / \mathrm{L}$ & $4.28 \pm 0.39 \mathrm{mg} / \mathrm{L}$ & $<0.00 \mathrm{I}$ \\
\hline $\begin{array}{l}\text { p value by repeat } \\
\text { measure ANOVA }\end{array}$ & $<0.00 \mathrm{I}$ & $<0.00 \mathrm{I}$ & $<0.00 \mathrm{I}$ & \\
\hline
\end{tabular}

rats. $^{12}$ However; the regularity effect of pioglitazone on inflammatory markers such as CRP has not been described. Hence the present study was designed to evaluate the effect of pioglitazone and gemfibrozil on serum CRP levels to evaluate if its anti-inflammatory action is shared by gemfibrozil or not as both the drugs share the effect on PPAR $\alpha$. The results of this study will predict the mechanism of anti-inflammatory effect of pioglitazone in hyperlipidemic non diabetic cases.

\section{METHODS}

This experimental animal study was started after taking approval from ethical committee of Post Graduate Medical Institute (PGMI), Lahore, Pakistan. A total of 27 adult healthy male Sprague Dawley rats, 7-8 week of age, weighing between $230-275 \mathrm{~g}$ were included in the study. They were purchased from National Institute of Health, Islamabad, Pakistan and were kept in animal house of PGMI, Lahore, Pakistan in iron cages under hygienic conditions. Exclusion criteria was animals with hyperglycemia or any other sign of disease. The room temperature was maintained at $25 \pm 2^{\circ} \mathrm{C}$ under I $/$ / $2 \mathrm{hr}$ day/night cycle. After one week of acclimatization rats were divided into three groups by simple random sampling and fed hyperlipidemic diet throughout study period of 8 weeks. Hyperlipidemic diet contained cholesterol $1.5 \%$, coconut oil $8.0 \%$ and sodium cholate $1.0 \% .^{12}$ After 4 weeks group $A$ (control) rats were given $2 \mathrm{ml} / \mathrm{kg}$ body weight of distilled water, group $B$ (experimental) rats were given $10 \mathrm{mg} / 2$ $\mathrm{ml} / \mathrm{kg}^{13}$ body weight of pioglitazone and group $\mathrm{C}$ (experimental) rats were given $10 \mathrm{mg} / 2 \mathrm{ml} / \mathrm{kg}^{14}$ body weight of gemfibrozil daily as a single morning dose. Both drugs were of pharmaceutical grade, dissolved in distilled water daily and given by oral route via I $\mathrm{ml}$ syringe.

Body weight of each rat was measured weekly and doses were adjusted accordingly. At baseline, after 4 weeks of high fat feeding and at end of experiment ( 4 weeks of high fat feeding and treatment with pioglitazone or gemfibrozil), blood sample was taken, after overnight fasting of 12 hours, by cardiac puncture under light anesthesia with a 27 gauge needle and put in serum gel (yellow tip) vacutainer. After clotting and centrifugation, serum was separated and stored at $4^{\circ} \mathrm{C}$ until analyzed for C-reactive protein. CRP in each sample was assayed by an immunoturbidimetric method by using a Spinreact kit Germany on automated chemistry analyzer Sysmex $\mathrm{KX}-2 \mathrm{I}$. Blood sugar level was estimated by oxidase method using standard Rendox kit Germany on a semi automated chemistry analyzer (Benchtop UK) at $4^{\text {th }}$ week to exclude diabetes.

Data was analyzed by SPSS 21 . After checking normal distribution by Shapiro Wilk test, it was expressed as mean $\pm S D$. Comparison between groups was made by ANOVA followed by post hoc Tukey's test. Mauchley's test of sphericity was applied to validate repeat measure ANOVA which was followed by post hoc analysis with Bonferroni adjustment.

\section{RESULTS}

Level of CRP in all groups was similar at 0 week. After high fat diet it increased in all groups at $4^{\text {th }}$ week. After treatment with pioglitazone it decreased at $8^{\text {th }}$ week but continued to increase in control and gemfibrozil treated groups (Table I).
Multiple comparisons by ANOVA revealed significant difference between groups at $8^{\text {th }}$ week only. Post hoc analysis disclosed that CRP level was significantly low is pioglitazone treated group compared to control and gemfibrozil groups. While difference between control and gemfibrozil was not significant (Table ll).

When repeat measure ANOVA was applied $p$ value was $<0.00 \mathrm{I}$ in each group (Table I). Post hoc analysis of each group revealed significant increase in CRP level from 0-4 and 0-8 weeks in all groups. From 4-8 week there was significant decrease in pioglitazone treated group, while significant increase in control and gemfibrozil treated group (Table III).

Blood sugar level was only measured at $4^{\text {th }}$ week to exclude diabetic rats, however; none of the rats developed diabetes. This test was not repeated at $8^{\text {th }}$ week.

\section{DISCUSSION}

Silent inflammation causes a significant contribution to the pathogenesis as well as complications of atherosclerosis ${ }^{15}$ and poses an enormous burden on public health system. There are several markers to detect this inflammation out of which the role of CRP cannot be denied. It has a long half-life of 19 hours, due to which it is a stable marker for cardiovascular status monitoring. It plays an important role in detecting subclinical diseases and assessing the wellbeing of average population. ${ }^{16}$

Objective of the study was to investigate the effects of pioglitazone in comparison

TABLE II: MULTIPLE COMPARISON OF C - REACTIVE PROTEIN LEVEL BETWEEN GROUPS AT $8^{\text {TH }}$ WEEKS BY POST HOC TUKEY'S TEST

\begin{tabular}{|c|c|c|c|}
\hline \multicolumn{2}{|c|}{ Group } & Mean difference & Significance \\
\hline \multirow{2}{*}{$\begin{array}{c}\text { A } \\
\text { (Control) }\end{array}$} & $\begin{array}{c}\text { B } \\
\text { (Pioglitazone) }\end{array}$ & 1.49 & $<0.001$ \\
\cline { 2 - 4 } & $\begin{array}{c}\text { C } \\
\text { (Gemfibrozil) }\end{array}$ & 0.14 & 0.665 \\
\hline $\begin{array}{c}\text { B } \\
\text { (Pioglitazone) }\end{array}$ & $\begin{array}{c}\text { C } \\
\text { (Gemfibrozil) }\end{array}$ & -1.35 & $<0.001$ \\
\hline
\end{tabular}


EFFECT OF PIOGLITAZONE AND GEMFIBROZIL ADMINISTRATION ON C-REACTIVE PROTEIN LEVELS IN NON-DIABETIC HYPERLIPIDEMIC RATS

TABLE III: MULTIPLE COMPARISON OF C - REACTIVE PROTEIN LEVEL BETWEEN STUDY TIMES WITHIN GROUPS

\begin{tabular}{|c|c|c|c|c|c|c|c|}
\hline \multicolumn{2}{|c|}{} & \multicolumn{2}{c|}{ Group A (Control) } & \multicolumn{2}{c|}{ Group B (Pioglitazone) } & \multicolumn{2}{c|}{ Group C (Gemfibrozil) } \\
\hline \multicolumn{2}{|c|}{$\begin{array}{c}\text { Time } \\
\text { (weeks) }\end{array}$} & $\begin{array}{c}\text { Mean } \\
\text { difference }\end{array}$ & Significance & Mean difference & Significance & Mean difference & Significance \\
\hline \multirow{2}{*}{0} & 4 & -0.953 & 0.002 & -0.962 & $<0.001$ & -0.921 & $<0.00 \mathrm{I}$ \\
\cline { 2 - 9 } & 8 & -1.828 & $<0.001$ & -0.294 & 0.009 & -1.603 & $<0.00 \mathrm{I}$ \\
\hline 4 & 8 & -0.874 & 0.005 & 0.668 & 0.002 & -0.682 & 0.048 \\
\hline
\end{tabular}

to gemfibrozil on CRP level of diet induced non diabetic hyperlipidemic Sprague Dawley rats. In this study young male Sprague Dawley rats were used because they are prone to develop hyperlipidemia as compared to their female counter parts. High lipid diet promotes atherosclerosis by generation of various inflammatory and pro oxidant elements. ${ }^{17}$ The basic reason for comparison between pioglitazone and gemfibrozil was that both are agonist of peroxisome proliferator activated receptor PPAR. Both improved lipid profile in our previous study. ${ }^{12}$ However pioglitazone acts on PPAR- $\alpha$ and PPAR-Y both whereas gemfibrozil only acts on PPAR- $\alpha$.

CRP level was significantly increased in all groups at $4^{\text {th }}$ week as compared to baseline. After treatment with pioglitazone it significantly decreased at $8^{\text {th }}$ week, although not up to baseline. Numerically level was slightly higher than baseline, but statistically the difference was not significant. Reason may be continued administration of atherogenic diet. Secondly it may be age related factor. Had another group of normal rats been added, it would have been interpreted better. A study conducted on hyperlipidemic rabbits demonstrated significantly lower level of CRP in pioglitazone treated animals as compared to control group after 18 weeks of treatment with $p$ value of $<0.0$ I. In our study CRP was lower in pioglitazone treated group as compared to control group with $p$ value of $<0.00$ I after 8 weeks of treatment. ${ }^{18}$ Clinical studies have also demonstrated antiinflammatory property of pioglitazone checked by measuring serum CRP level. In type 2 diabetes mellitus patients, pioglitazone treatment for 12 weeks decreased serum CRP level with $p$ value $<0.001$. $^{19}$ In another study on diabetic patients effect of pioglitazone was more than metformin with $p$ value 0.04 after 16 weeks of treatment. ${ }^{9}$ Even non-diabetic patients have shown significant decrease ( $p$ value 0.03 ) in CRP level after 24 weeks treatment with pioglitazone. ${ }^{10}$
In this study gemfibrozil failed to decrease the level of $\mathrm{C}$-reactive protein as compared to pioglitazone. This might be because pioglitazone is an agonist of both PPAR- $\alpha$ and PPAR-Y while gemfibrozil is PPAR- $\alpha$ agonist only. Other possibility may be because by acting through PPAR-Y pioglitazone also raises the level of plasma adiponectin. ${ }^{20}$ Adiponectin is a protein involved in glucose and fatty acid metabolism. Disturbed biosynthesis of adiponectin in diabetes mellitus, hyperlipidemia and metabolic syndrome predicts its contribution in pathogenesis of these diseases. ${ }^{21}$ Evidence suggests that adiponectin has anti-inflammatory effects. ${ }^{22}$ Apart from that pioglitazone has also shown to upregulate antioxidant stress genes in healthy volunteers. ${ }^{20}$

\section{CONCLUSION}

Results of this study demonstrate probable anti-inflammatory role of pioglitazone, evidenced by significant decrease in CRP level in non-diabetic hyperlipidemic rats in presence of continued high fat feeding while gemfibrozil is not effective.

\section{ACKNOWLEDGMENT}

Funds were provided by PGMI, Lahore, Pakistan. We appreciate cooperation of animal house and pathology laboratory staff.

\section{REFERENCES}

I. Mangge $\mathrm{H}$, Becker $\mathrm{K}$, Fuchs $\mathrm{D}$, Gostner JM. Antioxidants, inflammation and cardiovascular disease. World J Cardiol 2014 Jun 26;6 (6): 462 - 7 7. D O : I0.4330/wjc.v6.i6.462.

2. Ridker PM. Inflammation, Creactive protein, and cardiovascular disease: moving past the marker versus mediator debate. Cir Res 2014 Feb I4;II4(4):594-5. DOI: I0.1 |6I/CIRCRESAHA. | |4.3032| 5 .
3. Stancel N, Chen CC, Ke LY, Chu CS, Lu J, Sawamura T, et al. Interplay between CRP, atherogenic LDL, and LOX $-I$ and its potential role in the pathogenesis of atherosclerosis. Clin Chem 2016;62(2):320-7. DOI: 10.1373/clinchem.20I5.243923.

4. St-Onge MP, Zhang S, Darnell B, Allison DB. Baseline serum Creactive protein is associated with lipid responses to low-fat and highpolyunsaturated fat diets. J Nutr 2009; I39(4):680-3. DOI: I0.3945/jn. I08.09825I.

5. Rabkin SW, Langer A, Ur E, Calciu $C D$, Leiter LA. Inflammatory biomarkers CRP, MCP-I, serum amyloid alpha and interleukin- 18 in patients with HTN and dyslipidemia: impact of diabetes mellitus on metabolic syndrome and the effect of statin therapy. Hypertens Res $2013 ; 36(6): 550-8$. DOI: $10.1038 / \mathrm{hr} .2012 .214$.

6. Cunningham ML, Collins $B J$, Hejtmancik MR, Herbert RA, Travlos GS, Vallant MK, et al. Effect of PPAR- $\alpha$ agonist and widely used antihyperlipidemic drug gemfibrozil on hepatic toxicity and lipid metabolism. PPAR Res 2010;2010:681963. DOI: $10.1 \mid 55 / 2010 / 681963$.

7. Paumelle R, Staels B. Peroxisome proliferator-activated receptors mediate Pleiotropic action of statins. Circ Res 2007;100:1394-5. DOI: I0.1 |6 I/0 I.RES.0000269334.428 | 4.d2.

8. Sulaiman AA, Hussain SA, Jum'ma $K M$, Sigar AH. Evaluation of the antiinflammatory effect of Pioglitazone in experimental models of inflammation in rats. IraqiJ Pharm Sci 2009:30; I8(Suppl): I-6.

9. Genovese S, De Berardis G, Nicolucci A, Mannucci E, Evangelista $V$, Totani L, et al. Effect of pioglitazone versus metformin on cardiovascular risk markers in type 2 
diabetes. Adv Ther 2013 Feb $1 ; 30(2): 190-202$. DOI: I0.1007/s | 2325-0|3-0003-x.

10. Shokouh $P$, Joharimoghadam A, Roohafza H, Sadeghi M, Golabchi A, Boshtam M, et al. Effects of pioglitazone on asymmetric dimethylarginine and components of the metabolic syndrome in nondiabetic patients (EPICAMP Study): a double-blind, randomized clinical trial. PPAR Res 2013;2013:358074. DOI: I0.II55/2013/358074.

II. Grosso AF, de Oliveira SF, Higuchi Mde L, Favarato D, Dallan LA, da Luz PL. Synergistic antiinflammatory effect: simvastatin and pioglitazone reduce inflammatory markers of plasma and epicardial adipose tissue of coronary patients with metabolic syndrome. Diabetol Metab Syndr 2014 March;31;6(I):47. DOI: I0.I I86/I758-5996-6-47.

12. Hussian M, Arain AQ, Chiragh S. Pioglitazone improves serum lipid profile in diet induced hyperlipidaemicnon diabetic rats. J Pak Med Assoc 20 I 6 Oct;66(I0): I 286-90

13. Darwish SA, Abdel-Azeim T, Noureldeen NM, Abou Zeid A, Toussoun N. Fructose induced metabolic syndrome in rats, $A$ role for glitazones, fibrates and statins. Bull Alex Fac Med 2006;42(4): I 182-90.

14. Kim, M. PAR-5359, a well balanced PPAR $\alpha / Y$ dual agonist, exhibits equivalent antidiabetic and hypolipidemic activities in vitro and in vivo. Eur J Pharmacol 2008 Oct 24;595(I-3): I I9-25. DOI: 10.1016/j.ejphar.2008.07.066.

15. Willeit P, Thompson SG, Agewall S, Bergström G, Bickel H, Catapano $A L$, et al. Inflammatory markers and extent and progression of early atherosclerosis: Meta-analysis of individual-participant-data from 20 prospective studies of the PROGIMT collaboration. Eur J Prev Cardiol 2016;23(2):194-205. DOI: |0.1 |77/20474873|4560664.

16. Shrivastava AK, Singh HV, Raizada A, Singh SK. C-reactive protein, inflammation and coronary heart disease. Egyptian Heart J 2015;67(2):89-97.

17. Roberts CK, Barnard RJ, Sindhu RK, Jurczak M, Ehdaie A, Vaziri ND. A high-fat, refined-carbohydrate diet induces endothelial dysfunction and oxidant/antioxidant imbalance and depresses NOS protein expression. J Appl Physiol 2005
Jan;98(I):203-I0. DOI: I0. I I52/japplphysiol.00463.2004.

18. XuJ, Nie M, LiJ, Xu Z, Zhang M, Yan $Y$, et al. Effect of pioglitazone on inflammation and calcification in atherosclerotic rabbits. Herz 2017. DOI: I0.1007/s00059-0| 7-4620-z.

19. Moon JH, Kim HJ, Kim SK, Kang ES, Lee BW, Ahn CW, et al. Fat redistribution preferentially reflects the anti-inflammatory benefits of pioglitazone treatment. Metabolism 20II;60(2): I65-72. DOI: 10.1016/j.metabol.2009.12.007.

20. Sakatani $Y$, Miyoshi $T$, Oe H, Nakamura K, Saito Y, Morita H, et al. Pioglitazone prevents endothelial dysfunction induced by ischemia and reperfusion via up-regulating antioxidative effects: a human study. Eur Heart J 2013 ;34(suppl_I): P590.

21. Bhatt S. Adiponectin receptor: a potential target for diabetes, obesity and other disorders. Pharmacologyonline 20 I0; I: I I 7-30.

22. Ohashi K, Ouchi N, Matsuzawa Y. Anti-inflammatory and antiatherogenic properties of adiponectin. Biochimie 2012 Oct 31;94(I0):2।37-42. DOI: I0.1016/j.biochi.20I2.06.008.

\section{AUTHORS' CONTRIBUTIONS}

Following authors have made substantial contributions to the manuscript as under:

MH: Concept \& study design, acquisition of data, drafting the manuscript, final approval of the version to be published.

MM: Analysis \& interpretation of data, final approval of the version to be published.

ZZ \& SC: Drafting the manuscript, critical review, final approval of the version to be published.

Authors agree to be accountable for all aspects of the work in ensuring that questions related to the accuracy or integrity of any part of the work are appropriately investigated and resolved.

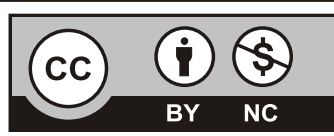

This is an Open Access article distributed under the terms of the Creative Commons Attribution-NonCommercial 2.0 Generic License. 